\title{
The effect of São Paulo's smoke-free legislation on carbon monoxide concentration in hospitality venues and their workers
}

\author{
Jaqueline S Issa, ${ }^{1}$ Tania M 0 Abe, ${ }^{1}$ Alexandre C Pereira, ${ }^{1}$ Maria Cristina Megid, ${ }^{2}$ \\ Cristina E Shimabukuro, ${ }^{2}$ Luis Sergio 0 Valentin, ${ }^{2}$ Marizete M da C Ferreira, ${ }^{2}$ \\ Moacyr R C Nobre, ${ }^{1}$ Ines Lancarotte, ${ }^{1}$ Antonio Carlos Pereira Barretto ${ }^{1}$
}

${ }^{1}$ Heart Institute, Smoking Cessation Program department, Medicine Faculty, University of São Paulo, SP, Brazil

${ }^{2}$ São Paulo State Center of Surveillance, São Paulo, Brazil

\section{Correspondence to} Dr Jaqueline Scholz Issa, Heart Institute, Medicine Faculty, University of São Paulo, Rua Dr Eneas de Carvalho Aguiar 44, 1 andar Bloco2, CEP, São Paulo 05403- 000, São Paulo, Brazil; jaqueline@incor.usp.br

Received 28 April 2010 Accepted 27 October 2010 Published Online First 25 November 2010

\section{(2) UNLOCKED}

This paper is freely available online under the BMJ Journals unlocked scheme, see http:// tobaccocontrol.bmi.com/site/ about/unlocked.xhtml

\section{ABSTRACT}

Background Studies have shown that there is no safe level of secondhand smoke (SHS) exposure and there is a close link between SHS and the risk of coronary heart disease and stroke. Carbon monoxide (CO) is one of the most important components present in SHS.

Objective To evaluate the impact of the smoking ban law in the city of Sao Paulo, Brazil, on the CO concentration in restaurants, bars, night clubs and similar venues and in their workers.

Methods In the present study we measured CO concentration in 585 hospitality venues. CO concentration was measured in different environments (indoor, semi-open and open areas) from visited venues, as well as, in the exhaled air from approximately 627 workers of such venues. Measurements were performed twice, before and 12 weeks after the law implementation. In addition, the quality of the air in the city during the same period of our study was verified.

Results The CO concentration pre-ban and pot-ban in hospitality venues was indoor area 4.57 (3.70) ppm vs 1.35 (1.66) ppm ( $p<0.0001)$; semi-open 3.79 (2.49) ppm vs 1.16 (1.14) ppm $(p<0.0001)$; open area 3.31 (2.2) ppm vs 1.31 (1.39) ppm ( $<<0.0001)$; smoking employees 15.78 (9.76) ppm vs 11.50 (7.53) ppm $(p<0.0001)$ and non-smoking employees 6.88 (5.32) ppm vs $3.50(2.21) \mathrm{ppm}(\mathrm{p}<0.0001)$. The average CO concentration measured in the city was lower than $1 \mathrm{ppm}$ during both pre-ban and post-ban periods. Conclusion São Paulós smoking-free legislation reduced significantly the $\mathrm{CO}$ concentration in hospitality venues and in their workers, whether they smoke or not.

\section{BACKGROUND}

Several recent studies clearly show that there is no safe level of exposure to secondhand smoke (SHS). The Conference of the Parties to the Framework Convention, ${ }^{1}$ the WHO International Agency for Research on Cancer, ${ }^{2}$ the US Surgeon General ${ }^{3}$ and the UK Scientific Committee on Tobacco and Health $^{4}$ all agree that SHS exposure is associated with a range of diseases, including cardiovascular heart disease and many types of cancer. For example, SHS exposure increases the risk of coronary heart disease by $25-30 \%$ and the risk of lung cancer by $20-30 \%{ }^{3}$

Previous experiences in other countries and cities show a reduction in cardiovascular events after the implementation of a smoking ban law in those places. This reduction is thought to be mainly associated with a reduction in SHS. ${ }^{5-9}$ Based on these experiences, the São Paulo state government approved smoke-free legislation in 2009, forbidding the consumption of all tobacco products in enclosed and partly closed collective sites, including public and private places, such as working environments, cultural establishments, pharmacies, bars, restaurants, movie theaters, theatres, hotels, supermarkets, nightclubs, schools, museums, cabs, banks, health institutions and others. The exception includes private residences, religious cult venues in which the tobacco product is part of the ceremony and sites specifically and exclusively designated for tobacco consumption.

After the smoking-ban law became public, it was necessary to create a campaign named "Tobaccofree and healthy environments" to show the viability of eliminating smoking from indoor and partly closed places, through coordinated actions between the São Paulo State Center of Surveillance and the Consumer Protection Agency. The main objective of this campaign was to visit the hospitality venues to inform and solidify behaviour changes that would make feasible the practice of the smoking-ban law. The Sao Paulo State Center of Surveillance was responsible for the measurements of $\mathrm{CO}$ in the hospitality venues and in their workers.

$\mathrm{CO}$ is a toxic, odourless, colourless, tasteless and non-irritating gas. $\mathrm{CO}$ is one of the most important pollutants in cigarette smoke and is exhaled by smokers during and after having smoked tobacco products. We chose $\mathrm{CO}$ as a biological marker of SHS because it is easy to measure, has a good correlation with SHS and it can be measured in both the environment and in the exhaled air of individuals at the same time.

The atmospheric concentration of $\mathrm{CO}$ is generally below $0.001 \%$, but it may be higher in metropolitan areas. It is formed from incomplete combustion of organic material and hydrocarbon combustion at high temperatures with an insufficient oxygen supply. Other common sources of $\mathrm{CO}$ generation include combustion of petroleum derogates by cars and coal ovens. The CO concentration in São Paulo city is monitored by the Environmental Agency of São Paulo (CETESB).

When inhaled, CO joins successfully with oxygen in the bloodstream to form carboxyhaemoglobin $(\mathrm{COHb}) . \mathrm{CO}$ can remain in the blood stream for up 
to 24 hours, depending on a range of factors including physical activity, gender and inhalation intensity. The half-life of $\mathrm{CO}$ in a person who breathes regular air is about 5 hours.

$\mathrm{CO}$ measurement is commonly used in smoking cessation programmes and is also used to evaluate the quality of the air in indoor social places, as it was observed in the study of Waring et $a{ }^{10}{ }^{10}$ which analysed bars in Austin, Texas, before and after smoking ban.

In spite of $\mathrm{CO}$ not being specific of cigarette smoke, in indoor places tobacco smoke is the most important source of $\mathrm{CO}$, as showed by Goniewicz et al ${ }^{11}$ Their study evaluated secondhand smoke in Polish bars by measuring $\mathrm{CO}$ concentration and concluded that the main source of $\mathrm{CO}$ is tobacco smoke.

Tual et a $^{12}$ analysed the impact of tobacco control policies on exhaled CO in almost 59000 non-smokers in 27 European Union countries and noticed a strong link between antismoking policies and the exposure to passive smoking. The mean exhaled $\mathrm{CO}$ was $1.6 \mathrm{ppm}$ in Ireland, which has a strong antismoking police, and $6.6 \mathrm{ppm}$ in Greece, without any antismoking police.

Some studies ${ }^{13}{ }^{14}$ show a strict relation between the CO concentration and the risk of cardiovascular events and have noted a reduction in hospital admissions due to cardiovascular events after smoking-ban laws having been implemented.

Despite the evidence of cardiovascular event reduction after smoking-ban laws, few studies have quantified the reduction of the SHS components, which can justify such events. Here, we have evaluated the $\mathrm{CO}$ concentration in hospitality venues and their workers before and after the smoking-ban law.

\section{METHODS}

The ethics committee for Research Project Evaluation (CAPPesq) of the Hospital das Clinicas, School of Medicine, University of São Paulo approved the study.

The first phase included the period prior to the implementation of the tobacco-free policy (from 23 July to 2 August 2009), and the second phase was performed approximately 12 weeks after the banning law was introduced (from 29 October to 7 November 2009), using the same agents, same places, on the same day of the week, same time of the day and with the same workers as were analysed in the first visit.

Approximately 100 agents from the Sao Paulo State Center of Surveillance were trained to use a $\mathrm{CO}$ monitor, to obtain a signed informed consent and to conduct data collection. They visited bars, restaurants, nightclubs and similar venues collecting data from the environment and from some workers at these places (two smoking and two non-smoking workers whenever possible). They were instructed to apply the informed consent to smoking and non-smoking workers of these venues and then to measure their exhaled CO. Ascertained workers were, preferentially, those working in closed spaces of the visited venues.

\section{Study sample}

According to the São Paulo Hotels and Restaurants Syndicate, ${ }^{15}$ there are more than 30000 restaurants, bars, nightclubs and similar places in the city of São Paulo. A total of 585 hospitality venues inside the city of São Paulo were visited before and after the tobacco-free policy was implemented. The sites were a sample of convenience. They were selected over a geographical range of the city, sampled from a large number of entertainment establishments in all five geographical zones: north, east, south, west and centre. The measurement of $\mathrm{CO}$ was done indoors, in partly closed spaces (semi-open), and in open spaces of the venues. The CO measurement of open areas was done in front of the main door of the establishment, keeping a close contact with the indoor area. The samples were obtained during the busiest period of the week-on Thursdays, Fridays or Saturdays between 21:00 and 03:00.

Measurements of exhaled air in venue workers, smokers or not, were also done. Only workers in good health were invited to participate in the study, and all of them provided written informed consent. We planned to get at least one smoker and one non-smoker from every establishment. They were questioned about their smoking status (non-smoker, have never smoked or is an ex-smoker (without smoking for at least 30 days); eventual smoker, have smoked at least one cigarette in the last 30 days; regular smoker, smoke every day), mean number of cigarettes smoked per day, sex and age.

\section{CO monitors}

The samples were collected with two types of portable $\mathrm{CO}$ measuring devices. The monitors use a sampling method that channels the gas sample directly over the sensor during the test. This ensures that the electrochemical sensor is exposed to the gas sample for the required length of time to give an accurate reading. The electrochemical sensor is designed to react to the presence of carbon monoxide and produces an output current proportional to the level of $\mathrm{CO}$. This is then read by the microprocessor and converted to display the equivalent parts per million (ppm). The first monitor used was the ToxCo (Bedfont Scientific; Rochester, England), a small portable device to measure environmental $\mathrm{CO}$ concentration, which has a display with two numbers - the first one shows the $\mathrm{CO}$ measure on real time and the second one shows the highest level achieved in the present measure. The second one was the PiCo (Bedfont Scientific; Rochester, England), which has a similar mechanism as the ToxCo, but measures exhaled human CO concentration. The measures in visited venues were done in real time, and were done in the centre of the establishments, avoiding contamination by ovens. Before starting the test, the person was instructed to hold his/her breath for 15 seconds and then exhale slowly into the mouthpiece. They were calibrated according to manufacturer's instruction. The $\mathrm{CO}$ monitors are certified by The National Physical Laboratory of the UK.

Data collected from venues were compared with data obtained by the CETESB in nine automatic stations located in different parts of São Paulo, covering the same area of our collected data. These automatic stations measure $\mathrm{CO}$ and other pollutants in the streets. Here, these data were used to test whether possible reductions in $\mathrm{CO}$ could be influenced by other conditions, like meteorological elements.

\section{Statistical analysis}

Descriptive statistics were calculated for $\mathrm{CO}$ level in both the pre-ban and post-ban periods across the whole dataset and then subdivided by location within the venue and venue type. Data are presented as means \pm SE. Pearson's correlation coefficients were used to explore correlations between different environments of a particular venue.

Differences in the pre-ban measurements according to venue type and measurement location were analysed by one-way and two-way analysis of variance. Differences between pre-ban and post-ban concentrations were analysed by one-way and twoway analysis of variance for repeated measures. Differences in expired $\mathrm{CO}$ concentrations in venue employees were analysed by a two-way analysis of variance for repeated measures (using time and smoking status as strata). Probability values of $\leq 0.05$ were considered statistically significant. Statistical analysis was carried out using SPSS V.13.0. 


\section{RESULTS}

\section{Venue level information}

We were able to collect data on 585 venues during the pre-ban period and on 559 venues during the post-ban period. No significant difference in pre-ban indoor $\mathrm{CO}$ measurements between venues that were or were not visited in the post-ban period was observed (mean value in venues visited twice 4.56 (3.69); mean value in venues visited only in the pre-ban period 4.42 (4.97); $p$ value $=0.86$ ). The main reason for not obtaining a paired visit was because some venues went out of business during the follow-up period.

A wide range of venue types was ascertained. In table 1 we present information regarding venue type and pre-ban and postban CO measurements in the three different environments sampled. We observed a significant difference between pre-ban measured CO levels and venue type only regarding closed environments $(p=0.04)$, and not in semi-open and open environments ( $p=0.08$ and $p=0.23$, respectively). This difference was due to higher mean CO levels in closed environments in bars and nightclubs compared with restaurants (5.02, 4.91, and, 4.01, respectively).

Regardless of venue type, a significant difference was verified regarding closed, semi-open, and open environments $(p<0.001$ for mean difference between environments, adjusted for venue type). As expected, significant correlations were observed between the studied environments in the pre-ban period (Pearson coefficient between closed and semi-opened: 0.84; closed and opened: 0.57 ; and semi-opened and opened: 0.70 , all with a $p$ value $<0.001$ ).

In the post-ban period, significant reductions in all study environments were observed (figure 1, table 1). As can be observed, and expected, although all reductions were highly significant, the absolute and relative reductions observed for closed environments, regardless of venue type, were higher than those observed for open spaces. In closed environments, in the pre-ban period $180(30.8 \%)$ venues had CO concentrations above the level of $4.5 \mathrm{ppm}$ (associated with increased overall health risk). In the post-ban period, only eight (1.4\%) venues had CO measurements above this threshold.

Interestingly, for closed environments a significant interaction between CO reduction and venue type was identified ( $p=0.01$ for the interaction term). This was observed owing to a higher $\mathrm{CO}$ reduction observed in bars and nightclubs compared with that observed in restaurants. One interpretation of this result is that in the post-ban period, no significant difference was observed between venue type and closed environment CO levels $(p=0.39)$, as opposed to the pre-ban period, where bars and nightclubs had significantly higher values. In fact, in the postban period survey no significant difference between CO levels and environment (open, semi-open and closed), or venue type (restaurant, bar, nightclub or other) was observed any longer, thus suggesting equalisation with outdoor levels (table 1).

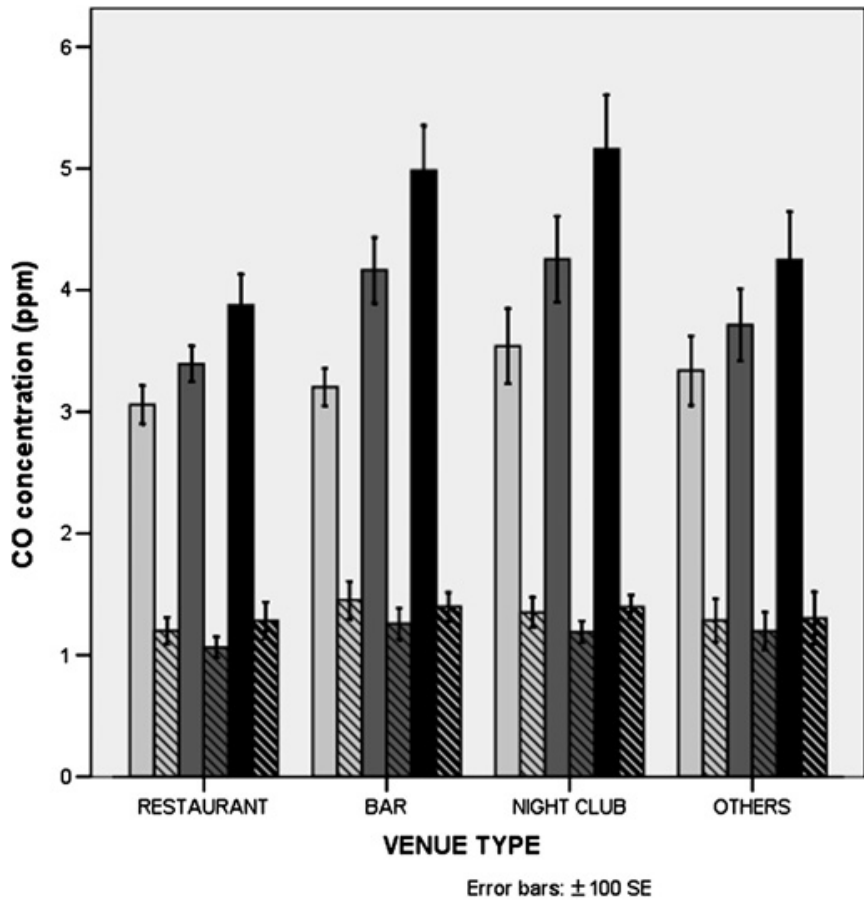

Figure 1 Absolute values on measured environment $\mathrm{CO}$ concentrations before and after ban implantation according to venue type and environment type.

The quality of the air in the city during the same period of our study through the air quality databank from the Environmental Agency of São Paulo (CETESB) was as follows: in study days of the pre-ban period: $0.94 \mathrm{ppm}(0.075 \mathrm{SE}, \mathrm{CI} 95 \% 0.77$ to 1.12 , minimum 0.31 , maximum 1.59 for mean levels, and min 0.1 , max 2.4 for individual data points), in the study days of the post-ban period $0.66 \mathrm{ppm}(0.073 \mathrm{SE}$ and CI $95 \% 0.49$ to 0.83 , min 0.09 , max 2.40 for mean levels, and min 0.0, max 3.2 for individual data points).

\section{Individual level information}

Our survey design was able to collect information of $\mathrm{CO}$ level on 627 employees in the pre-ban period, 359 non-smoking and 268 smoking employees. Employees were mainly male (147 vs 39 for smoking; 232 vs 45 for non-smoking). Mean age was 33.8 (10.1) years for smoking and 34.2 (11.5) years for non-smoking employees. In the post-ban period, we were able to re-ascertain the CO levels of 464 employees, 277 non-smoking and 187 smoking employees. The mean number of cigarettes in the pre-ban period was of 14 (SD 10), and 12 in the post-ban period (SD 9), $\mathrm{p}=0.02$.

The main reason for not obtaining a higher rate of repeated measures of $\mathrm{CO}$ level was because of the survey design, in which venues were re-visited at the same time and day of the week of

Table 1 Pre-ban and post-ban mean CO level according to venue type and sampled environment

\begin{tabular}{|c|c|c|c|c|c|c|c|c|c|c|c|c|c|c|c|}
\hline \multirow[b]{3}{*}{ Venue type } & \multicolumn{15}{|c|}{ Environment } \\
\hline & \multicolumn{2}{|c|}{$\begin{array}{l}\text { Closed } \\
\text { pre-ban }\end{array}$} & \multicolumn{2}{|c|}{$\begin{array}{l}\text { Closed } \\
\text { post-ban }\end{array}$} & \multirow[b]{2}{*}{ p Value } & \multicolumn{2}{|c|}{$\begin{array}{l}\text { Semi-opened } \\
\text { pre-ban }\end{array}$} & \multicolumn{2}{|c|}{$\begin{array}{l}\text { Semi-opened } \\
\text { post-ban }\end{array}$} & \multirow[b]{2}{*}{ p Value } & \multicolumn{2}{|c|}{ Open pre-ban } & \multicolumn{2}{|c|}{ Open post-ban } & \multirow[b]{2}{*}{ p Value } \\
\hline & Mean & SD & Mean & SD & & Mean & SD & Mean & SD & & Mean & SD & Mean & SD & \\
\hline Restaurant & 4.01 & 3.39 & 1.29 & 1.66 & $<0.001$ & 3.49 & 2.09 & 1.11 & 1.06 & $<0.001$ & 3.16 & 1.98 & 1.22 & 1.30 & $<0.001$ \\
\hline Bar & 5.02 & 4.27 & 1.35 & 1.22 & $<0.001$ & 4.14 & 3.02 & 1.21 & 1.37 & $<0.001$ & 3.23 & 1.74 & 1.43 & 1.68 & $<0.001$ \\
\hline Nightclub & 4.91 & 3.21 & 1.30 & .82 & $<0.001$ & 4.01 & 2.70 & 1.15 & .73 & $<0.001$ & 3.50 & 2.33 & 1.33 & 0.97 & $<0.001$ \\
\hline Other & 4.64 & 3.94 & 1.67 & 2.87 & $<0.001$ & 3.58 & 2.32 & 1.21 & 1.16 & $<0.001$ & 3.74 & 3.23 & 1.31 & 1.25 & $<0.001$ \\
\hline
\end{tabular}


the pre-ban survey, and many surveyed individuals in the pre-ban survey were off-duty on those days or some of them were no longer employed at the venue. It should be mentioned that no significant difference in mean $\mathrm{CO}$ levels between individuals who were revisited or not revisited was observed ( $p=0.23$, CO mean level of 10.47 and 11.44 for revisited and not revisited individuals, respectively).
As expected, a significantly higher mean $\mathrm{CO}$ level was observed in employees who smoked than in employees who did not smoke $(p<0.001$ in the pre-ban survey; $p<0.001$ in the postban survey). In the pre-ban period, significant correlations were observed between measured $\mathrm{CO}$ level in indoor environments and expired $\mathrm{CO}$ levels in both smoking $(\mathrm{p}<0.001)$ and nonsmoking employees $(p<0.001)$. It is interesting to note, however,
Figure 2 Relation between exhaled $\mathrm{CO}$ levels in smoking and non-smoking venue employees ( $\mathrm{X}$ axis) and environment $\mathrm{CO}$ levels of visited venues (Y axis). (A) Non-smoking employees pre-ban period; (B) Smoking employees pre-ban period; (C) Non-smoking employees post-ban period; (D) Smoking employees post-ban period.
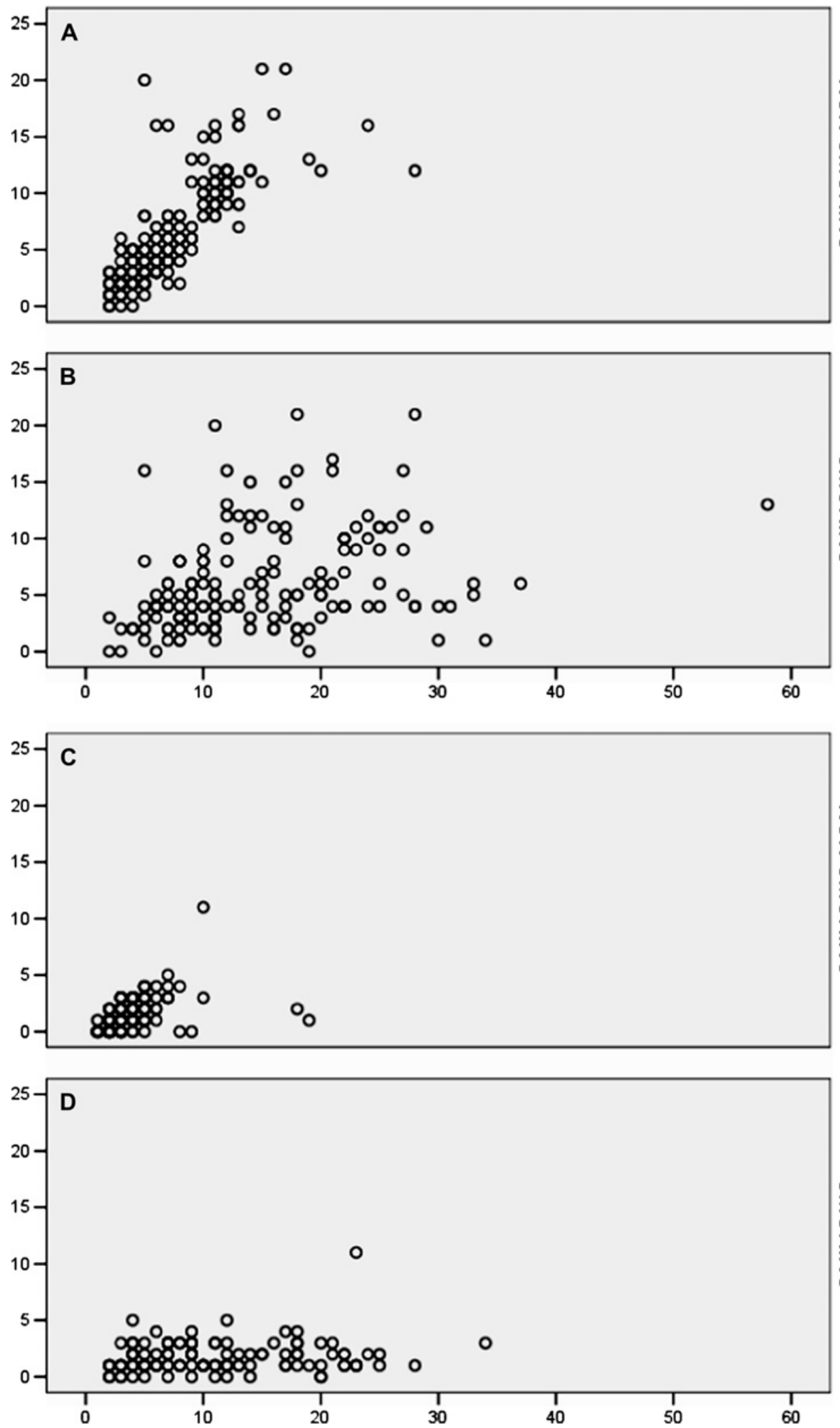
that the correlation coefficient was much higher in non-smoking than in smoking employees ( 0.79 and 0.32 , respectively), thus suggesting that the indoor environment was important in predicting expired $\mathrm{CO}$ levels in both smoking and, especially, in non-smoking employees (figure 2).

Table 2 presents data on the pre-ban and post-ban periods for both smoking and non-smoking employees. Overall, a significant reduction in $\mathrm{CO}$ levels was observed for both smoking and nonsmoking employees after the smoking-ban $(p<0.001)$. This occurred irrespective of venue type $(p=0.58$ for the interaction term between survey time and venue type). Interestingly, the degree of $\mathrm{CO}$ reduction was also independent of the smoking status (figure 3 ).

If the correlation structure of smoking status and environmental CO levels is dissected, an interesting pattern can be seen in the post-ban period. For non-smoking employees a significant, but much weaker, correlation existed between environment $\mathrm{CO}$ levels and expired $\mathrm{CO}$ levels $(\mathrm{p}=0.001$, correlation coefficient 0.22 ). On the other hand, for smoking employees one could no longer observe any correlation between environment CO levels and expired CO levels ( $p=0.17$, correlation coefficient 0.11 ). This can be better observed in figure 2 ( $\mathrm{A}$ and $\mathrm{B}$ for the correlation structure in the pre-ban period, and $\mathrm{C}$ and $\mathrm{D}$ for the correlation structure in the post-ban period).

Another important point regarding exhaled $\mathrm{CO}$ concentrations after the ban is that $\mathrm{CO}$ reductions were verified even in smoking employees that continued to smoke after the ban implementation (although a higher reduction was observed, as expected, in smoking employees who reduced the number of cigarettes). This suggests that reduction of expired $\mathrm{CO}$ after the ban was regardless of changing smoking habits in venue's employees (figure 4).

\section{DISCUSSION}

The association between active smoking and cardiovascular disease has been known for many decades, and more recently SHS has also been recognised as a risk factor for coronary disease. Reducing public exposure to cigarette smoke can have immediate implications on human health. In the last two decades, some studies ${ }^{5-9}$ have shown a significant reduction in cardiovascular hospital admissions after the implementation of smoking-ban ordinances.

The current study analysed the effects of the smoking ban on levels of $\mathrm{CO}$ in restaurants, bars and similar venues in the city of São Paulo, Brazil. There was a clear reduction in the concentration of $\mathrm{CO}$ in almost all visited places. Measured $\mathrm{CO}$ reductions were especially significant in indoor areas, but were also seen in semi-open and open areas of these sites. Regarding cooking stoves, although they can influence $\mathrm{CO}$ measurement, a significant difference between the first and the second measurement was observed even in restaurants, where this

Table 2 Pre-ban and post-ban CO measurements at the individual level

\begin{tabular}{|c|c|c|c|c|c|}
\hline \multirow[b]{2}{*}{ Venue type } & \multirow[b]{2}{*}{ Smoking status } & \multicolumn{2}{|c|}{ Pre-ban period } & \multicolumn{2}{|c|}{ Post-ban period } \\
\hline & & Mean & SD & Mean & SD \\
\hline \multirow[t]{2}{*}{ Restaurant } & Smoking & 15.67 & 9.8 & 11.48 & 8.38 \\
\hline & Non-smoking & 6.32 & 3.49 & 3.44 & 2.02 \\
\hline \multirow[t]{2}{*}{ Bar } & Smoking & 16.47 & 10.39 & 10.75 & 7.25 \\
\hline & Non-smoking & 7.22 & 5.85 & 3.75 & 2.85 \\
\hline \multirow[t]{2}{*}{ Nightclub } & Smoking & 17.73 & 11.61 & 13.49 & 6.97 \\
\hline & Non-smoking & 6.94 & 6.69 & 3.29 & 1.68 \\
\hline \multirow[t]{2}{*}{ Other } & Smoking & 10.61 & 3.79 & 7.18 & 3.03 \\
\hline & Non-smoking & 7.91 & 3.32 & 3.5 & 2.01 \\
\hline
\end{tabular}

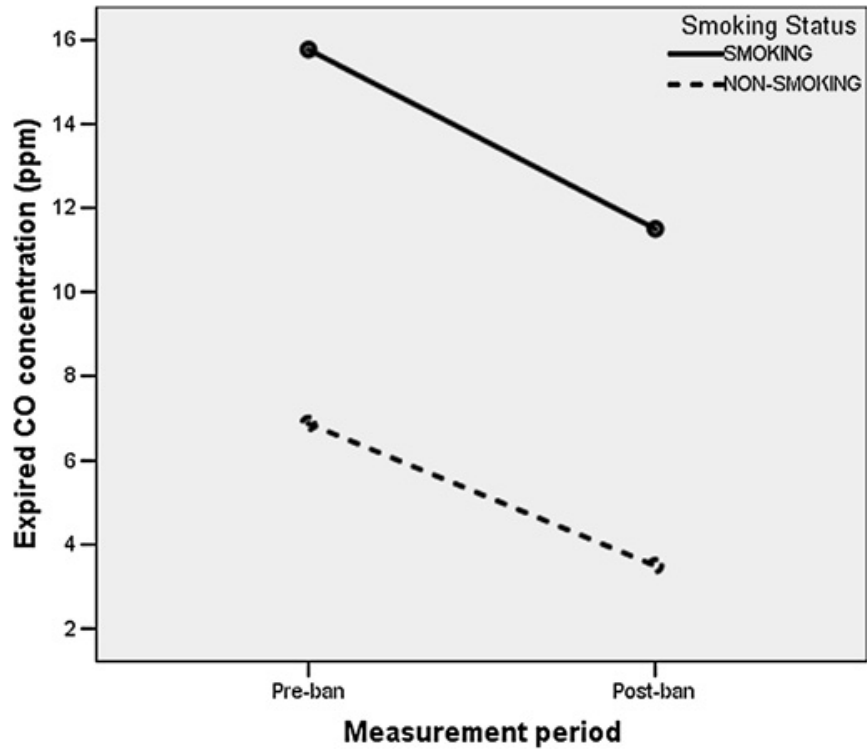

Figure 3 Exhaled $\mathrm{CO}$ reduction after ban implementation in venue employees according to smoking status.

confounding effect is more common. An interesting fact is that restaurants were the places with the lowest pre-ban $\mathrm{CO}$ average among all venues types. These data were corroborated by Erazo et $a l^{16}$ who analysed the air nicotine concentration in bars and restaurants in Chile and noticed a lower concentration of nicotine in restaurants compared to bars in Santiago, Chile.

Some studies have used other biological markers of SHS pre-smoking ban and post-smoking ban. ${ }^{17-19}$ They analysed other components of SHS like particulate matter concentrations, volatile organic compound and cotinine levels, and they found

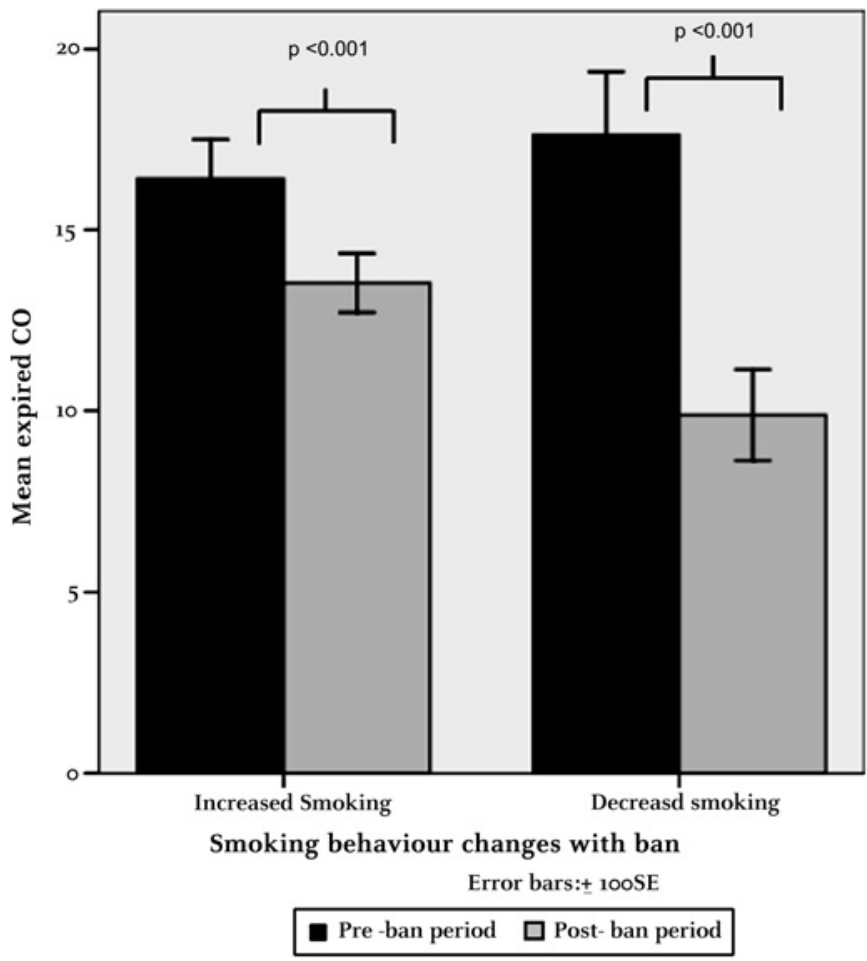

Figure 4 Mean expired CO levels in smoking employees before and after ban implementation according to changes in smoking behaviour after the ban. 
significant reductions in all these products. In fact, these studies have also shown that there is a tight correlation between reductions in exhaled $\mathrm{CO}$ and smoke-related particulate matter, suggesting that the use of exhaled $\mathrm{CO}$ is, indeed, a good surrogate in studies with a large number of places and individuals studied. Goodman et $a l^{20}$ showed the effects of the Irish smoking ban on respiratory health of bar workers and in the air quality in Dublin pubs, studying particulate matter in 42 pubs and exhaled $\mathrm{CO}$ and salivary cotinine of 81 barmen, before and after the ban law. They showed a significant reduction of $83 \%$ in particulate matter concentration, a reduction of $79 \%$ and $81 \%$ in the exhaled $\mathrm{CO}$ concentration and in salivary cotinine of nonsmokers and ex-smokers, respectively. No changes were seen in current smokers, but there were clear sample size limitations for this analysis.

Specifically, this study showed that after the ordinance, there was a reduction of $70 \%$ in the $\mathrm{CO}$ concentration in hospitality venues. The reduction was close to threefold in enclosed areas. By comparing the values of $\mathrm{CO}$ concentration in the streets monitored by CETESB during the same period of the study, it is possible to understand that the $\mathrm{CO}$ concentration reduction observed in such places cannot be attributed to external factors like climatic changes or season variability. The average $\mathrm{CO}$ CETESB streets concentration before and after the smoking-ban law was lower than $1 \mathrm{ppm}$ in the study periods. In fact, it is interesting to observe that in the post-ban period $\mathrm{CO}$ concentration in closed, semi-open and open venue areas became similar to the measured in streets monitored by CETESB.

Other important observation of this study was that the exhaled CO for the non-smoking workers became similar to the levels observed in regular non-smoking citizens who live in São Paulo city according to Issa et al, ${ }^{21}$ but the most relevant observation was that even among smokers who increase cigarette consumption after the ban law we found significant reductions in the $\mathrm{CO}$ concentration of exhaled air, proving that the SHS influence on the $\mathrm{CO}$ concentration in smokers was independent of changes in cigarette consumption.

There are some potential limitations. Owing to our sample size we were not able to conduct measures of other biological markers of SHS, such as particulate matter concentrations. In addition, interesting data regarding behavioural changes that led to smoking habit changes in smoking employees were not obtained and we could only measure the result of these changes in the number of cigarettes smoked. Finally, we have little health

\section{What is already known on this subject}

Cardiovascular events are reduced a few months after smokingban laws are implemented. Although carbon monoxide (CO) is one of the most important components present in SHS, few studies to date have aimed at quantifying the reduction of $\mathrm{CO}$ exposure after smoking-ban laws.

\section{What this paper adds}

We were able to describe significant environment and individual reductions in $\mathrm{CO}$ concentrations. The effect of the smoke-ban law was detectable in all environments of visited venues and, most importantly, in both non-smoking and smoking employees. information on studied individuals, which precluded the use of more complex regression models adjusting for potential confounders of the observed changes (eg, prevalent pulmonary conditions, smoking history, etc).

The consequences of the observed $\mathrm{CO}$ reduction are not well known, but it clearly indicates the unequivocal influence of SHS in $\mathrm{CO}$ exhaled air concentration in individuals who work in these venues. Thus, one can speculate that the significant reduction obtained in $\mathrm{CO}$ concentrations after adoption of tobacco smoke-free legislation could be causally related to the reduction in cardiovascular events incidence observed in many places where this law has already been adopted.

In conclusion, our findings are consistent both at the environment and individual levels and they reinforce the necessity for supporting the campaign for tobacco free environments.

Acknowledgements São Paulo State Center of Surveillance agents for the data collected, and Patricia Shigeeda Bossoni for the English support.

Funding This study was funded by Fundação Zerbini and São Paulo State Department of Health.

Competing interests $\mathrm{Jl}$ has consulted for Pfizer and has been principal investigator for clinical trials of smoking cessation medications funded by Pfizer and other clinical trials funded by Lilly. The other authors report no conflicts.

Patient consent Obtained

Ethics approval This study was conducted with the approval of the CAPPESQ ethics committee for research project evaluation of the Hospital das Clinicas, School of Medicine, University of São Paulo.

Provenance and peer review Not commissioned; externally peer reviewed.

\section{REFERENCES}

1. World Health Organization. Conference of the Parties to the WHO Framework Convention on Tobacco Control. http://www.who.int/gb/fctc/PDF/cop2/ FCTC COP2 17P-en.pdf (accessed 9 Dec 2009).

2. World Health Organization/International Agency for Research on Cancer IARC. Tobacco smoke and involuntary smoking: summary of data reported and evaluation. Geneva. Monographs on the Evaluation of Carcinogenic Risks to Humans. 2004. http://monographs.iarc.fr/ENG/Monographs/vol83/volume83.pdf laccessed 9 Dec 2009)

3. U.S. Department of Health and Human Services. The health consequences of involuntary exposure to tobacco smoke: a report of the Surgeon General. Atlanta, U.S Department of Health and Human Services, Centers for Disease Control and Prevention, Coordinating Center for Health Promotion, National Center for Chronic Disease Prevention and Health Promotion. Office on Smoking and Health, 2006. http://www.surgeongeneral.gov/library/secondhandsmoke/report/fullreport.pdf (accessed 9 Dec 2009).

4. Scientific Committee on Tobacco and Health. Update of Evidence on Health Effects of Secondhand Smoke. London: Scientific Committee on Tobacco and Health, 2004. http://www.dh.gov.uk/prod consum dh/idcplg?ldcService=GET FILE\&dID= 13632 \&Rendition=Web (accessed 9 Dec 2009).

5. Pell JP, Haw S, Cobbe S, et al. Smoke free legislation and hospitalizations for acute coronary syndrome. N Engl J Med 2008;359:482-91.

6. Bartecchi C, Alsever RN, Nevin-Woods C, et al. Reduction in the incidence of acute myocardial infartion associated with a citywide smoking ordinance. Circulation 2006;114:1490-6.

7. Juster HR, Loomis BR, Hinman TM, et al. Declines in hospital admissions for acute myocardial infarction in New York State after implementation of a comprehensive smoking ban. Am J Public Health 2007;97:2035-9.

8. Barone-Adesi F, Vizzini L, Merletti F, et al. Short-term effects of Italian smoking regulation on rates of hospital admission for acute myocardial infarction. Eur Heart $J$ 2006:20:2468-72.

9. Lightwood JM, Glantz SA. Declines in acute myocardial infarction after smokefree laws and individual risk attributable to secondhand smoke. Circulation 2009;120:1373-9.

10. Waring MS, Siegel JA. An evaluation of the indoor air quality in bars before and after a smoking ban in Austin, Texas. J Expo Sci Environ Epidemiol 2007:17:260-8.

11. Goniewicz ML, Czogala J, Kosmider L, et al. Exposure to carbon monoxide from second-hand tobacco smoke in Polish pubs. Cent Eur J Public Health 2009;17:220-2.

12. Tual S, Piau JP, Jarvis MJ, et al. Impact of tobacco control policies on exhaled carbon monoxide in non-smokers. J Epidemiol Community Health 2010;64:554-6. 
13. McGrath JJ. Biological plausibility for carbon monoxide as a copollutant in PM epidemiologic studies. Inhal Toxicol 2001;12:91-107.

14. Bell ML, Peng RD, Dominici F, et al. Emergency hospital admissions for cardiovascular diseases and ambient levels of carbon monoxide: results for 126 United States urban counties, 1999-2005. Circulation 2009:120:949-55

15. Sindicato dos hotéis, restaurantes, bares e similares de São Paulo. http://www. sinhores-sp.com.br/dados tecnicos.htm (accessed 12 Feb 2010).

16. Erazo M, Iglesias V, Droppelmann A, et al. Secondhand tobacco smoke in bars and restaurants in Santiago, Chile: evaluation of partial smoking ban legislation in public places. Tob Control 2010;19:469-74.

17. Bates MN, Fawcett J, Dickson S, et al. Exposure of hospitality workers to environmental tobacco smoke. Tob Control 2002;11:125-9.
18. McNabola A, Broderick B, Johnston P, et al. Effects of the smoking ban on benzene and 1,3-butadiene levels in pubs in Dublin. J Environ Sci Health A Tox Hazard Subst Environ Eng 2006;41:799-810.

19. Proescholdbell SK, Foley KL, Johnson J, et al. Indoor air quality in prisons before and after implementation of a smoking ban law. Tob Control 2008;17:123-7.

20. Goodman $\mathbf{P}$, Agnew $M$, McCaffrey $M$, et al. Effects of the Irish smoking ban on respiratory health of bar workers and air quality in dublin pubs. Am J Respir Crit Care Med 2007;175:840-5.

21. Issa JS, Ogawa T. Carbon monoxide concentration in exhaled air of smokers and now-smoker residents in São Paulo City, Brazil. In: Annual Meeting of the Society for Research on Nicotine and Tobacco. Joint Conference of SRNT and SRNT-Europe. Proceedings and On-Site Program. Ireland. April 27-30, 2009, Dublin, Ireland: 2009:42. 